\title{
Vasoactive Intestinal Polypeptide and Pituitary Adenylate Cyclase-Activating Polypeptide Activate Hyperpolarization- Activated Cationic Current and Depolarize Thalamocortical Neurons In Vitro
}

\author{
Qian-Quan Sun, David A. Prince, and John R. Huguenard \\ Department of Neurology and Neurological Sciences, Stanford University School of Medicine, Stanford, California 94305
}

\begin{abstract}
Ascending pathways mediated by monoamine neurotransmitters regulate the firing mode of thalamocortical neurons and modulate the state of brain activity. We hypothesized that specific neuropeptides might have similar actions. The effects of vasoactive intestinal peptide (VIP) and pituitary adenylate cyclase-activating polypeptide (PACAP) were tested on thalamocortical neurons using whole-cell patchclamp techniques applied to visualized neurons in rat brain slices. VIP $(2 \mu \mathrm{M})$ and PACAP $(100 \mathrm{nM})$ reversibly depolarized thalamocortical neurons ( $7.8 \pm 0.6 \mathrm{mV} ; n=16)$, reduced the membrane resistance by $33 \pm 3 \%$, and could convert the firing mode from bursting to tonic. These effects on resting membrane potential and membrane resistance persisted in the presence of TTX. Morphologically diverse thalamocortical neurons located in widespread regions of thalamus were all depolarized by VIP and PACAP38. In voltage-clamp mode, we found that VIP and PACAP38 reversibly activated a hyperpolarization-activated cationic current $\left(I_{\mathrm{H}}\right)$ in thalamocortical neurons and altered voltage- and time-dependent activation properties of the current. The effects of VIP on membrane conductance were abolished by the hyperpolarization-activated cyclic-nucleotide-gated channel (HCN)-specific antagonist ZD7288, showing that HCN channels are the major target of VIP modulation. The effects of VIP and PACAP38 on HCN channels were mediated by PAC $_{1}$ receptors and cAMP. The actions of PACAP-related peptides on thalamocortical neurons suggest an additional and novel endogenous neurophysiological pathway that may influence both normal and pathophysiological thalamocortical rhythm generation and have important behavioral effects on sensory processing and sleep-wake cycles.
\end{abstract}

Key words: vasoactive intestinal polypeptide; pituitary adenylate cyclase-activating polypeptide; thalamocortical neurons; cAMP; $I_{\mathrm{H}}$; HCN channels; depolarization

\section{Introduction}

Thalamocortical neurons exhibit two distinct functional states, characterized by tonic and burst firing (Jahnsen and Llinas, 1984a,b), that are associated with different levels of consciousness (for review, see Steriade and McCarley, 1990). Rhythmic and synchronous burst firing occurs during slow-wave sleep and paroxysmal events such as absence seizures. Tonic firing, in contrast, underlies activity during waking and rapid eye movement (REM) sleep and allows for a faithful, linear relay of sensory information to the neocortex. Steady depolarization of thalamocortical neurons causes a transition from burst to tonic firing mode, associated with development of an alert behavioral state (for review, see Steriade and McCarley, 1990; McCormick and Bal, 1997). In the past 10 years, several lines of evidence have suggested that the interaction between ascending neurotransmitter systems and several ion channels, particularly those mediating a leak $\mathrm{K}^{+}$conductance and a hyperpolarization-activated nonselective cation conductance $\left[I_{\mathrm{H}}\right.$ and hyperpolarization-activated cyclic-

Received Dec. 6, 2002; revised Jan. 23, 2003; accepted Jan. 24, 2003.

This work was supported by National Institute of Neurological Disorders and Stroke Research Grant NS12151 and by the Pimley Research and Training Funds. We are grateful to Isabel Parada for excellent assistance in the immunocytochemistry experiments.

Correspondence should be addressed to John R. Huguenard at the above address. E-mail:

John.Huguenard@stanford.edu.

Copyright $\odot 2003$ Society for Neuroscience $\quad 0270-6474 / 03 / 232751-08 \$ 15.00 / 0$ nucleotide-gated channels (HCN)] (cf. Ludwig et al., 1998; Santoro et al., 2000), are responsible for the transition between firing modes observed in thalamocortical neurons (for review, see McCormick, 1992b; McCormick and Bal, 1997). Monoaminergic nerve fibers originating from the brainstem, hypothalamus, and basal forebrain containing 5-HT, noradrenaline (NA), and histamine form major components of the ascending neurotransmitter system. These neurotransmitters activate $I_{\mathrm{H}}$ channels on thalamocortical relay cells (Pape and McCormick, 1989; McCormick and Pape, 1990a,b; McCormick and Williamson, 1991; for review, see McCormick, 1992b) or block leak $\mathrm{K}^{+}$currents in these neurons (McCormick and Prince, 1988; McCormick, 1992a). However, in addition to these classical neurotransmitters, other endogenous substances such as peptides may affect $I_{\mathrm{H}}$ channels and, thus, modulate thalamic excitability and cell firing mode.

Anatomical studies have demonstrated abundant peptidergic projections into mammalian thalamus. Recent evidence suggests that several endogenous neuropeptides, including NPY, somatostatin, and nociceptin/orphanin FQ, activate G-proteindependent inwardly rectifying $\mathrm{K}^{+}$channels and hyperpolarize thalamocortical neurons and/or reticular neurons (Sun et al., 2001, 2002; Meis et al., 2002), whereas the peptides cholecystokinin (Cox et al., 1995) and orexin (Bayer et al., 2002) depolarize relay or thalamic reticular neurons via inhibition of leak $\mathrm{K}^{+}$cur- 
rents. In the rodent thalamus, a dense network of pituitary adenylate cyclase-activating polypeptide (PACAP)-containing fibers is present in central nuclei (Köves et al., 1991), whereas vasoactive intestinal polypeptide (VIP) mRNA is detected in both relay nuclei and part of the nucleus reticularis (Burgunder et al., 1999). The PACAP peptide contains 38 aa and shares $68 \%$ identity with VIP. Therefore, PACAP and VIP belong to the VIP-glucagongrowth hormone-releasing factor-secretin superfamily (Vaudry et al., 2000). Three classes of PACAP/VIP receptors have been cloned, namely $\mathrm{PAC}_{1}$ receptors, which have higher binding affinities for PACAP $(<10 \mathrm{nM})$ than VIP, and $\mathrm{VPAC}_{1}$ and $\mathrm{VPAC}_{2}$ receptors, which have equal binding affinities for PACAP and VIP $(<10 \mathrm{~nm})$. Abundant expression of $\mathrm{PAC}_{1}$ receptors and lower levels of $\mathrm{VPAC}_{1}$ and $\mathrm{VPAC}_{2}$ receptors have been documented in most thalamic nuclei (Vaudry et al., 2000), suggesting broad effects on thalamocortical functions. However, the physiological roles of VIP/PACAP in thalamocortical activation are not clear. In the CNS and the peripheral nervous system, $\mathrm{PAC}_{1}$ receptors are known to stimulate cAMP formation (Vaudry et al., 2000), which in turn is known to have potent activating effects on $I_{\mathrm{H}}$ channels (Ludwig et al., 1998; Lüthi and McCormick, 1998; Santoro and Tibbs, 1999; Wainger et al., 2001). PACAP and VIP modulate a variety of ion channels, such as $\mathrm{N}$-type $\mathrm{Ca}^{2+}$ channels (Zhu and Yakel, 1997), small conductance $\mathrm{Ca}^{2+}$-activated $\mathrm{K}^{+}$ channels (Haug and Storm, 2000) and sodium-dependent conductances (Kohlmeier and Reiner, 1999); however, their effects on $I_{\mathrm{H}}$ channels have not been examined. Therefore, we tested the hypothesis that VIP and PACAP regulate the thalamocortical neuronal firing mode through actions on $I_{\mathrm{H}}$.

\section{Materials and Methods}

Slice preparation. All experiments were performed using a protocol approved by the Stanford Institutional Animal Care and Use Committee. Young Sprague Dawley rats [12-20 d of age; postnatal day 12 (P12)-P20] were deeply anesthetized with pentobarbital sodium $(55 \mathrm{mg} / \mathrm{kg})$ and decapitated. The brains were quickly removed and placed into cold $\left(\sim 4^{\circ} \mathrm{C}\right.$ ) oxygenated slicing medium containing (in $\mathrm{mM}$ ): $2.5 \mathrm{KCl}, 1.25$ $\mathrm{NaH}_{2} \mathrm{PO}_{4}, 10 \mathrm{MgCl}_{2}, 0.5 \mathrm{CaCl}_{2}, 26 \mathrm{NaHCO}_{3}, 11$ glucose, and 234 sucrose. Tissue slices (300-400 $\mu \mathrm{m}$ ) were cut in the horizontal plane using a vibratome (TPI, St. Louis, MO), transferred to a holding chamber, and incubated $\left(35^{\circ} \mathrm{C}\right)$ for at least $1 \mathrm{hr}$ before recording. Individual slices were then transferred to a recording chamber fixed to a modified microscope stage and allowed to equilibrate for at least $30 \mathrm{~min}$ before recording. Slices were minimally submerged and continuously superfused with oxygenated physiological saline at $4.0 \mathrm{ml} / \mathrm{min}$. Recordings were obtained at $35 \pm 1{ }^{\circ} \mathrm{C}$. The physiological perfusion solution contained (in $\mathrm{mm}$ ): $126 \mathrm{NaCl}, 2.5 \mathrm{KCl}, 1.25 \mathrm{NaH}_{2} \mathrm{PO}_{4}, 2 \mathrm{MgCl}_{2}, 2 \mathrm{CaCl}_{2}, 26 \mathrm{NaHCO}_{3}$, and 10 glucose. All solutions were gassed with $95 \% \mathrm{O}_{2}-5 \% \mathrm{CO}_{2}$ to a final $\mathrm{pH}$ of 7.4 .

Whole-cell patch-clamp recording. Whole-cell recordings were obtained using visualized slice patch techniques (Edwards et al., 1989) and a modified microscope (Axioskop; Zeiss, Thornwood, NY) with a fixed stage. A low-power objective $(2.5 \times)$ was used to identify the various thalamic nuclei, and a high-power water immersion objective $(40 \times)$ with Nomarski optics and infrared video was used to visualize individual neurons.

Recording pipettes were fabricated from capillary glass (M1B150F-4; World Precision Instruments, Sarasota, FL), using a Sutter Instruments (Novato, CA) P80 puller, and had tip resistances of 2-5 M $\Omega$ when filled with the intracellular solutions below. An Axopatch1A amplifier (Axon Instruments, Foster City, CA) was used for voltage- and current-clamp recordings. Access resistance in whole-cell recordings ranged from 4 to $12 \mathrm{M} \Omega$, was stable during the recording period, and was electronically compensated in voltage-clamp experiments by $50-75 \%$. Current and voltage protocols were generated using pClamp software (Axon Instruments). The following software packages were used for data analysis:
Clampfit (Axon Instruments), Winplot (courtesy of N. Dale, St. Andrews University, Fife, UK), and Origin (Microcal Software, Northampton, MA). The whole-cell patch pipette saline was composed of (in mM): 100 K-gluconate, $13 \mathrm{KCl}, 9 \mathrm{MgCl}_{2}, 0.07 \mathrm{CaCl}_{2}, 10$ EGTA, $10 \mathrm{HEPES}, 2 \mathrm{Na}_{2}$ ATP, and $0.4 \mathrm{Na}-\mathrm{GTP}$. The $\mathrm{pH}$ was adjusted to 7.4, and the osmolarity was corrected to $280 \mathrm{mosm} / \mathrm{l}$. This solution was also used as pipette saline for current-clamp recordings.

Drugs. Drugs were applied focally through a multibarrel microperfusion pipette that was positioned within $1 \mathrm{~mm}$ of the cell. VIP/PACAP analogs: concentrated VIP (Peninsula Laboratories, Belmont, CA) stock solutions were dissolved in ultrapure water to a final concentration of 0.2 $\mathrm{M}$ and stored in $\mathrm{a}-70^{\circ} \mathrm{C}$ freezer. Stock VIP solutions were diluted in physiological saline to final concentrations of $100 \mathrm{~nm}$ to $2 \mu \mathrm{M} 1 \mathrm{hr}$ before use. Unless otherwise noted, a concentration of $1 \mu \mathrm{M}$ was used. Concentrated PACAP38 (Peninsula Laboratories) and $\left[\mathrm{Ala}^{11,22,28}\right]$ VIP (Tocris, Ballwin, MO) solutions were also stored at $-70^{\circ} \mathrm{C}$. Aliquots were diluted to a final concentration in physiological solution just before use and applied via multibarrel focal perfusion. The following ion channel blockers and chemicals were used: bicuculline methiodide (Sigma, St. Louis, MO), TTX (Sigma), ZD7288 (Tocris), and 8-(4-chlorophenylthio)cAMP (8-cpt-cAMP; Sigma).

Statistics. All data are presented as mean \pm SEM unless otherwise stated. Analysis by Student's $t$ test was performed for paired and unpaired observations unless otherwise stated. $p$ values of $<0.05$ were considered statistically significant.

\section{Results}

\section{VIP and PACAP reversibly depolarize thalamocortical neurons and change their firing mode}

Whole-cell patch-clamp recordings were made predominantly from neurons located in the somatosensory region [ventrobasal (VB) complex] of the thalamus. In current-clamp mode, the average membrane resting potential recorded from thalamocortical neurons in vitro was $-63 \pm 1 \mathrm{mV}(n=16)$. The mean membrane input resistance, determined from the application of $1 \mathrm{sec}$ hyperpolarizing current steps $(-50 \mathrm{pA})$, was $188 \pm 22 \mathrm{M} \Omega(n=16)$. A series of constant-duration hyperpolarizing and depolarizing current pulses $( \pm 100 \mathrm{pA}, 200 \mathrm{msec})$ were applied to the relay neurons every $10 \mathrm{sec}$, and the effects of exogenous VIP on the excitability of relay neurons were studied. Exposure of neurons to VIP $(2 \mu \mathrm{M})$ elicited robust and at least partially reversible membrane depolarizations in 16 of 16 cells (Figs. 1A, 2A, 3A3, summary in Fig. $2 D)$. Local or bath application of VIP $(2 \mu \mathrm{M})$ depolarized relay neurons by $7.8 \pm 0.6 \mathrm{mV}(n=16 ; p<0.001$ vs controls) (Figs. $1 A, 2 A, B, D, 3 A 3$ ).

The VIP-mediated depolarizations were long-lasting, normally requiring at least $20 \mathrm{~min}$ for washout (Figs. $1 A, 2 A, 3 A$ ), and recovery was often incomplete (Figs. $2 A, 3 A 3$ ). The slow reversal of the VIP depolarization does not seem to be an artifact of whole-cell patch-clamp recordings, because under the same conditions in other experiments, G-protein-coupled NPY receptor-mediated hyperpolarizing responses were rapidly and completely reversible during an equivalent period (cf. Sun et al., 2001). The long-lasting effects mediated by VIP and PACAP suggest that perhaps a diffusible second messenger, with either longer-lasting effects on target ion channels or slower inactivation, was activated by VIP and PACAP.

The VIP-induced alterations in membrane potential were associated with changes in membrane resistance as measured by responses to current steps (after nulling the VIP-induced membrane depolarizations; see responses to hyperpolarizing current pulses in Figs. 1C1,C3). The average maximum input resistance in VIP was $127 \pm 8 \mathrm{M} \Omega(n=16)$, which was $67 \pm 3 \%(p<0.01)$ of controls. Both depolarization and decreased membrane resistance persisted in the presence of TTX $(1 \mu \mathrm{M})$ (Fig. 1B). Under 


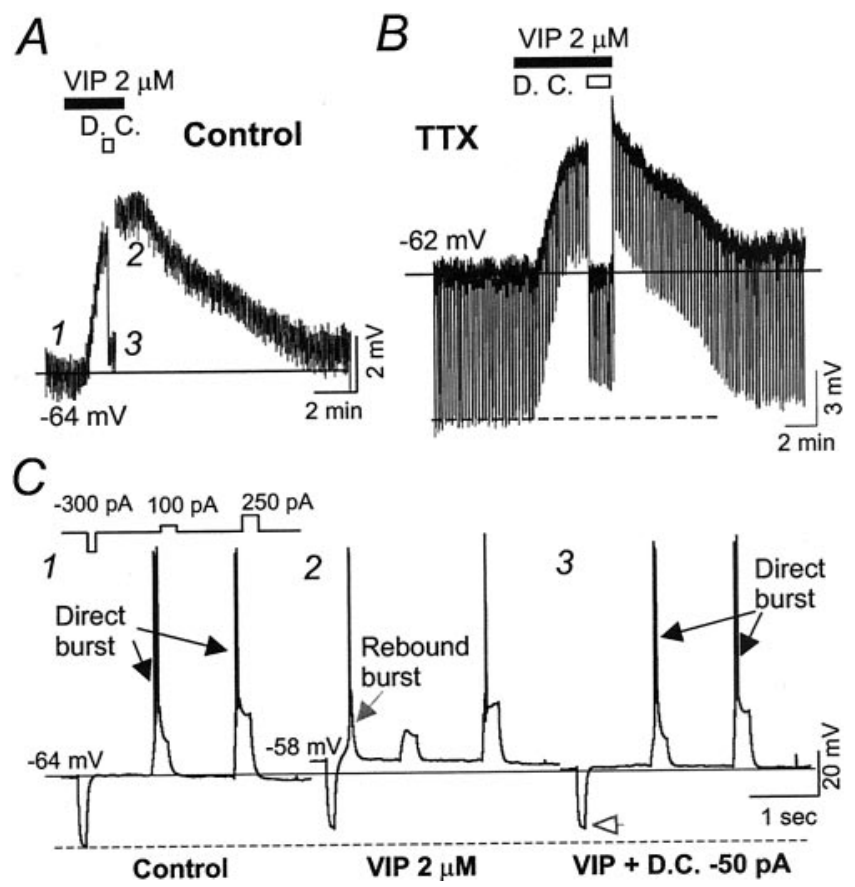

Figure 1. VIP induces depolarizations of resting membrane potentials in thalamocortical neurons. $A$, Locally applied VIP (2 $\mu \mathrm{m}, 4 \mathrm{~min})$ induced long-lasting depolarization $(6 \mathrm{mV})$ of membrane potential. The effects of VIP recovered to baseline level after $\sim 20 \mathrm{~min}$ of washout. The solid black horizontal line indicates level of resting membrane potential in the control solution. $B$, Continuous current-clamp recording of another cell showing reversible effects of VIP (2 $\mu \mathrm{M}, 4 \mathrm{~min}$, black bar) in the presence of TTX $(1 \mu \mathrm{M})$. Vertical lines indicate responses to $500 \mathrm{msec}$ current steps $(-20 \mathrm{pA})$ applied at $0.1 \mathrm{~Hz}$. The solid horizontal line indicates level of resting membrane potential in controls. The dashed horizontal line indicates control amplitude of membrane responses to hyperpolarizing current steps $(-20 \mathrm{pA})$. C, Current-clamp recording from the same neuron depicted in $A$ showing typical responses to a series of current steps ranging from -300 to $+250 \mathrm{pA}$ under control conditions ( 1) and during VIP application (2, 3). C3, A steady hyperpolarizing current $(-50 \mathrm{pA})$ was applied to the same neuron during VIP application to restore the resting membrane potential toward the control level, resulting in restoration of the directly evoked burst discharge. Black arrows in $C 1$ and $C 3$ indicate bursts evoked by depolarizing current pulses. Note that the hyperpolarizing current evoked a rebound lowthreshold spike during VIP application (C2, gray arrow) but not under control conditions or after the membrane was repolarized in C3. Traces in C were obtained at points 1-3 in A. The solid black horizontal line indicates level of resting membrane potential in control. The dashed horizontal line indicates amplitude of membrane responses to hyperpolarizing $(-300 \mathrm{pA})$ current pulses. The open gray arrowhead in $C 3$ shows the smaller voltage deflection obtained in the presence of VIP, indicating a conductance increase. D. C., Depolarizing current.

these conditions VIP $(2 \mu \mathrm{M})$ produced comparable membrane potential depolarization $(6.4 \pm 1.2 \mathrm{mV}$ in TTX; $p>0.5$ vs VIP depolarizations in controls; $n=5)$ and alteration of membrane resistance ( $61 \pm 7 \% ; p>0.5$ vs VIP actions in controls). These results suggest that direct activation of postsynaptic VIP receptors on the recorded cells mediated PACAP/VIP effects on membrane potential in relay neurons.

Thalamocortical neurons exhibit tonic and burst firing modes (cf. Jahnsen and Llinas, 1984a,b; McCormick and Prince, 1987; Steriade and McCarley, 1990; McCormick and Bal, 1997). In relay neurons with relatively hyperpolarized resting membrane potentials (less than $-63 \mathrm{mV} ; n=8$ ) (Fig. 1C), low-threshold burst discharges were reliably elicited by small depolarizing current steps (100-200 pA, $0.2 \mathrm{sec}$ ) (Figs. 1C, 2 B1, 3A1) (cf. Jahnsen and Llinas, 1984a,b). In seven of eight such hyperpolarized neurons, exposure to VIP caused robust depolarization and abolished directly evoked burst discharges (Figs. $1 C, 2 B 2$ vs $B 1,3 A 1, A 2$ ). In five of these eight neurons, burst discharge was replaced by tonic
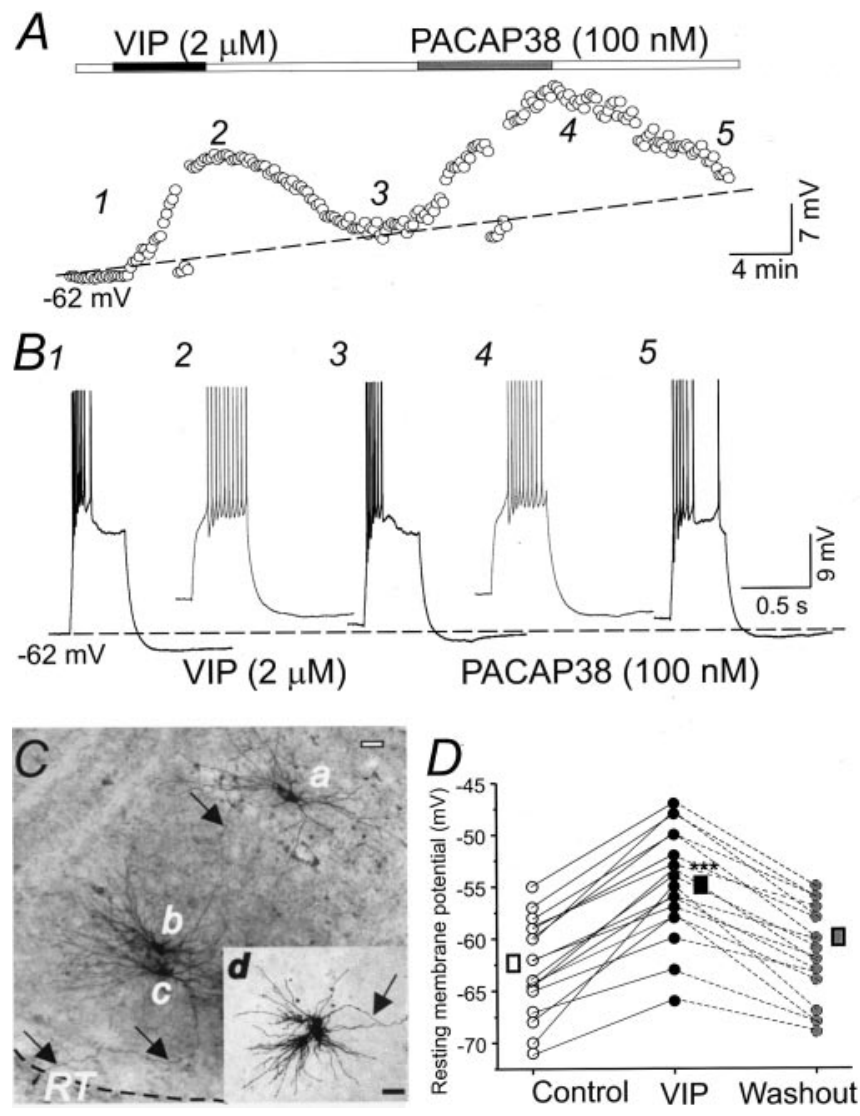

Figure 2. Morphologically distinct thalamocortical neurons are depolarized by VIP and PACAP. A, Resting membrane potential of a thalamocortical neuron during control, VIP application (2 $\mu \mathrm{m}$, filled black bar), VIP washout, PACAP38 application (100 nm, filled gray bar), and PACAP38 washout. Locally applied VIP (2 $\mu \mathrm{M}, 3 \mathrm{~min}$ ) induced long-lasting depolarization (6 $\mathrm{mV}$ ) of membrane potential that was largely reversible on washout. PACAP38 (100 nм) mimicked the effects of VIP on resting membrane potential. $B$, Current-clamp responses evoked by current steps ( $100 \mathrm{pA}, 0.5 \mathrm{sec}$ ) in the cell shown in $A$. The dashed black line in $A$ and $B$ indicates control resting membrane potential. Traces $1-5$ in $B$ were obtained at points indicated by the numbers in $A$. C, Photomicrograph of three biocytin-filled thalamocortical neurons in the ventral posterior nucleus. Scale bar, $50 \mu \mathrm{m}$. Arrows show a thalamocortical projecting axon, originating from cell $a$ and passing through the dendrites of cells $b$ and $c$, and branched collaterals in the reticular nucleus $(R T)$. Inset, Biocytin-filled thalamocortical neuron $(d)$ in the ventral lateral nucleus from a different slice. The membrane responses of these four cells and 12 others are shown in B.D, Resting membrane potentials in control solution (open circles) during VIP application (1 $\mu \mathrm{m}$, black circles) and 20 min after VIP washout (gray circles) in 16 thalamocortical neurons. Rectangles indicate mean values for resting potentials of the population in control solution (open), at peak of the VIP-induced depolarization (black), and after $\sim 20$ min of washout (gray). ${ }^{* * *} p<0.001$.

firing (Fig. $2 B 2$ vs $B 1,3 A 1, A 2$ ). The inhibitory effects of VIP on burst generation could be reversed by electronically nulling the effects on resting membrane potentials (Fig. $1 C 3$ vs $C 2)(n=7)$. PACAP38 (100 nM) mimicked the effects of VIP on resting membrane potential $(7 \pm 2 \mathrm{mV}$ depolarization; $n=4 ; p<0.05$ vs controls) (Fig. $2 A, B)$, membrane conductance $(134 \pm 19 \mathrm{M} \Omega$ vs $178 \pm 33 \mathrm{M} \Omega$ in controls; $n=4 ; p<0.05$ ), and firing mode (Fig. $2 B 4$ vs B3). These effects of VIP and PACAP38 are similar to the previously described depolarizing effects of classical neurotransmitters, such as 5-HT, NA, and histamine, on relay neurons (Pape and McCormick, 1989; McCormick and Pape, 1990a,b; McCormick and Williamson, 1991). In cells with more depolarized membrane potentials (positive to $-64 \mathrm{mV} ; n=8$; data not shown), VIP perfusion caused depolarization that resulted in a slightly increased tonic spontaneous firing rate (data not shown; 
$n=8)$. In summary, these results show that a common effect of VIP- and PACAP-mediated depolarization is to shift from burst mode to tonic firing mode.

Assessment of the morphologies of biocytin-filled cells, whose responses to VIP had been examined, revealed that thalamocortical neurons with different gross structures (Fig. $2 C$, cell $a-d$ ) were depolarized to a similar extent. Cells located in widespread regions of the thalamus all responded to VIP (ventral posteromedial thalamic nuclei, seven neurons; ventral posterolateral and ventral lateral nuclei, six neurons; ventromedial thalamic nuclei, two neurons; posterior thalamic nuclei, five neurons). No notable differences in VIP sensitivity were detected among cells from these different anatomical locations. Therefore, VIP and PACAP modulation is present in a diverse group of thalamocortical neurons.

\section{VIP activation of $I_{H}$}

Voltage-clamp recordings were made from thalamocortical neurons to determine the ionic mechanisms underlying the VIP-mediated depolarization of resting membrane potential. A series of hyperpolarizing voltage steps (1-2 sec) elicited large hyperpolarization-activated inward currents that showed a slow sigmoidal lag before reaching steady-state peak levels (data not shown). Activation could be fitted with a single exponential decay in 8 of 16 neurons. The time constant $(\tau)$ of activation showed voltage dependence and varied from 100 to $2000 \mathrm{msec}$ at -130 to $-80 \mathrm{mV}$ (Figs. 4A1,A2, 5A3) (cf. McCormick and Pape, 1990; Munsch and Pape, 1999). The activation reached steady-state value during prolonged ( $>1 \mathrm{sec}$ ) hyperpolarizing steps (Figs. 3B1, 4A1, 5A1, 6A1). To determine the voltage dependence of $I_{\mathrm{H}}$ activation, we measured the tail current amplitudes at a fixed membrane potential $(-130 \mathrm{mV})$ (Fig. 4A1, $I_{\text {tail }}$ ) (cf. Ludwig et al., 1998) after hyperpolarizing voltage steps to different test potentials. Activation curves were then fitted by a Boltzmann relationship $I / I_{\max }=\left\{1+\exp \left[\left(V+V_{1 / 2}\right) / K\right]\right\}$ to obtain the half-maximal activation $\left(V_{1 / 2}\right)$ and slope $(K)$. In the majority of cells tested, the tail currents could be well fitted with a Boltzmann relationship (Fig. 4A2,B1). The membrane potential at half-maximal activation was $-88 \pm 2.5 \mathrm{mV}$ in $\mathrm{VB}$ relay neurons (Fig. $4 B 1)(n=11)$, similar to that observed in relay neurons of mice (Santoro et al., 2000) and in other studies in rats (cf. Munsch and Pape, 1999).

The addition of VIP $(1 \mu \mathrm{M})$ reversibly enhanced $I_{\mathrm{H}}$ activation but had little effect on currents elicited at membrane potentials more positive than $-50 \mathrm{mV}$ (Figs. 3B3, $4 \mathrm{B1}$ ). Additional analysis of $I_{\mathrm{H}}$ activation curves recorded in the presence of VIP revealed significant rightward shifts toward more depolarized potentials in half-activation potential $(7.2 \pm 1 \mathrm{mV} ; n=11 ; p<0.001$ vs controls) (Fig. 4B1,B2). This shift resulted in a significant increase in the currents activated between -60 and $-70 \mathrm{mV}(66 \pm$ $4 \% ; n=11)($ Fig. $4 B 1, B 4)(p<0.001)$. However, it only resulted in a $30 \pm 2 \%$ enhancement of currents elicited at $-120 \mathrm{mV}$ (Fig. $4 B 1, B 3)(n=11 ; p<0.001)$. The VIP-mediated enhancement of $I_{\mathrm{H}}$ was also accompanied by reversible acceleration of the activation time constant (Fig. 5A1,A2). This shortening of activation time constant occurred in a voltage-dependent manner, with larger changes occurring at more depolarized test potentials (Fig. $5 A 3)(n=5)$. At $-100 \mathrm{mV}$, the activation time constant measured under control conditions varied from 500 to $750 \mathrm{msec}$ with a mean value of $636 \pm 20 \mathrm{msec}(n=8)$. Exposure of relay neurons to VIP significantly shortened the activation time constant in seven of eight cells, with a mean value of $481 \pm 23 \mathrm{msec}(n=8$; $p<0.01$ vs controls and washout) (Fig. 5B1,B2).

A specific inhibitor of $I_{\mathrm{H}}, \mathrm{ZD} 7288(50 \mu \mathrm{M})$ (BoSmith et al., 1993), was applied to determine whether additional ionic conductances might contribute to the VIP-mediated modulation of membrane properties in relay neurons. Constant hyperpolarizing voltage-clamp steps $(-100 \mathrm{mV}, 1 \mathrm{sec})$ (Fig. 6 B1) were applied to relay neurons at $0.1 \mathrm{~Hz}$. Switching local perfusate from control saline to VIP-containing saline caused enhancement of the inward currents (Fig. 6A1). The addition of ZD7288 significantly reduced control hyperpolarization-activated currents from $989 \pm 21$ to $445 \pm 20$ pA (Fig. 6 A1) $(n=8 ; p<0.01$ vs predrug). After the effects of ZD7288 reached a steady-state level, VIP was added to the local perfusate, and under these conditions VIP had no additional effect on currents evoked by voltage steps ( $446 \pm 18$ pA; $p>0.5$ vs ZD7288; $n=6$ ) (Fig. 6A1,A2). In another occlusion experiment, voltage ramps (from -50 to $-130 \mathrm{mV}$ ) were applied to thalamocortical neurons, and the effects of VIP on 


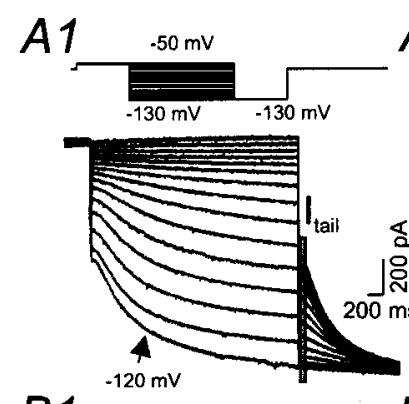

B1

A2

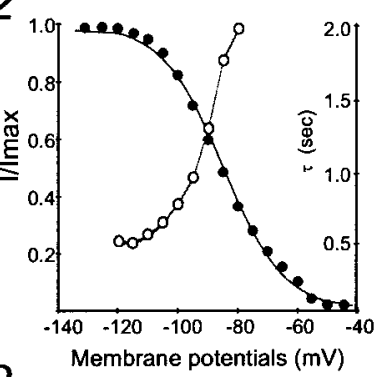

$B 2$
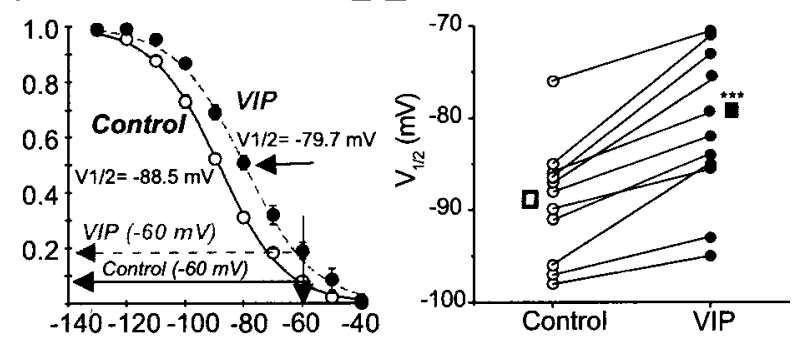

B3

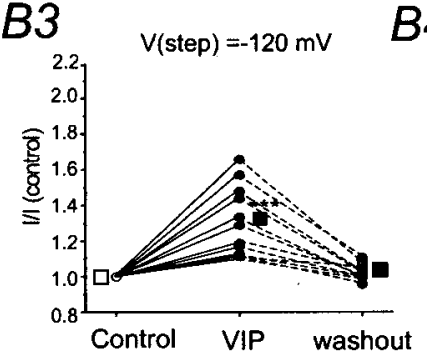

B4

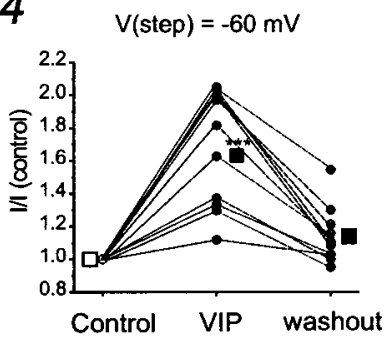

Figure 4. Voltage-dependent modulation of $I_{H}$ by VIP. $A$, Voltage-clamp recordings from a relay neuron showing currents elicited by hyperpolarizing voltage steps $(1 \mathrm{sec})$ from -50 to $-120 \mathrm{mV}$ in $10 \mathrm{mV}$ increments (above) under control conditions. $V_{\text {hold }}=-50 \mathrm{mV}$. Note that voltage commands and current traces are shown on different time bases. Gray traces overlying black traces are single exponential fits of current traces. $A 2$, The normalized conductance determined from tail currents ( filled circles, measured at latency indicated by filled gray bar in A1) was plotted versus voltage and fitted with a Boltzmann relationship, $I / I_{\max }=\{1+\exp [(V+$ $\left.\left.\left.V_{1 / 2}\right) / K\right]\right\}$, under control conditions, where $V_{1 / 2}=-86 \mathrm{mV}$ and $K=10$. The time constant of decay $(\tau)$, obtained from fitted curves in $A 1$, was plotted versus voltage (open circles and gray line). $B 1$, Normalized $I_{H}$ conductance, determined from mean tail current relative to that obtained at $-140 \mathrm{mV}$, as a function of voltage fitted with a Boltzmann relationship in the absence (open circles and black solid line; $n=11$ ) and presence (filled circles and gray dashed line; $n=$ 11) of VIP. B2, The half-activation voltages $\left(V_{1 / 2}\right)$ for $I_{H}$ in the absence (open circles) and presence (filled circles) of VIP for each neuron of $B 1$. Open (controls) and filled (in VIP) squares show the averaged $V_{1 / 2}$ values for each condition $(p<0.001 ; n=11) . B 3, B 4$, Normalized mean peak current amplitude at $-120 \mathrm{mV}(B 3)$ and $-60 \mathrm{mV}$ (B4) in control solution (open circles), during VIP application (black circles), and 20 min after VIP washout, measured from traces similar to those in $A 1$ ( $n=11)$. Open (controls) and filled (in presence of VIP) squares show averaged current values for each condition $\left({ }^{* * *} p<0.001\right)$. Note that VIP caused an $\sim 60 \pm$ $4 \%$ increase in currents elicited by steps to $-60 \mathrm{mV}$ but only a $30 \pm 2 \%$ increase in currents elicited by steps to $-120 \mathrm{mV}$.

instantaneous currents were studied in the presence of the $I_{\mathrm{H}}$ channel inhibitor ZD7288. In six such neurons tested, VIP had no significant effect on the currents elicited by voltage ramps (Fig. $6 B 1, B 2)(n=6)$, suggesting that $I_{\mathrm{H}}$ channels are the major targets of VIP modulation.

\section{VIP- and PACAP-mediated effects on $I_{H}$ are mediated by}

$\mathrm{PAC}_{1}$ receptors and cAMP

To establish the pharmacological profile of the VIP-mediated effects on $I_{\mathrm{H}}$, various concentrations of VIP and selective VPAC and $\mathrm{PAC}_{1}$ receptor agonists were applied to relay neurons. We used voltage steps $(-100 \mathrm{mV}, 2 \mathrm{sec})$ to elicit $I_{\mathrm{H}}$, and the effects of
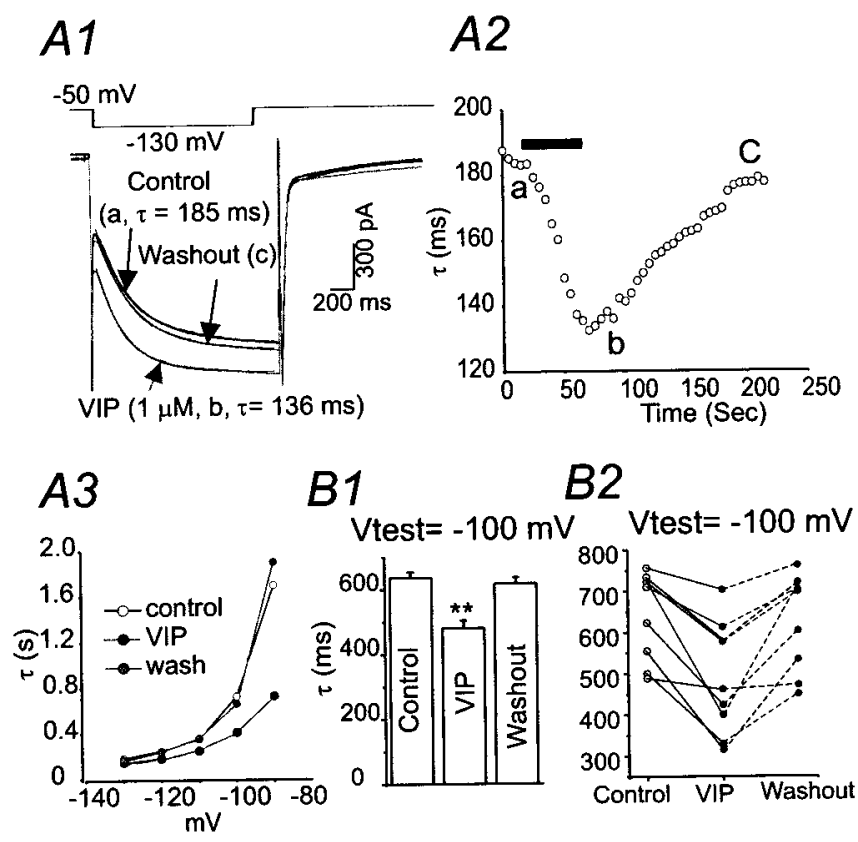

Figure 5. Acceleration of $I_{H}$ activation kinetics by VIP. $A 1$, Currents elicited by hyperpolarizing steps to $-130 \mathrm{mV}$ from a holding potential of $-50 \mathrm{mV}$ under control conditions $(a)$, during addition of VIP $(b)$, and after VIP washout (c). Thin superimposed darker solid lines are single exponential fits to current traces. $A 2$, The time constant of the exponential fit $(\tau)$ for the same experiment plotted versus time. Each circle shows the $\tau$ value for a single response evoked at 0.1 Hz. Black bar, VIP application. A3, Exponential time constants, obtained from a different relay neuron, plotted against test membrane potential under control conditions (open circles), during VIP application (black circles), and during washout (gray circles). B1, Mean exponential time constants for currents elicited by $-100 \mathrm{mV}$ steps in the control period, during VIP perfusion and after $20 \mathrm{~min}$ of washout. Columns show the average mean value for approximately eight responses evoked at $0.1 \mathrm{~Hz}$ in each of eight neurons; ${ }^{* *} p<0.01$. B2, Activation time constants for currents elicited by steps to $-100 \mathrm{mV}$ in the control period (open circles), during VIP perfusion (black circles), and after 20 min of washout ( gray circles) for each neuron of $B 1$.

$20 \mathrm{nM}, 50 \mathrm{nM}, 100 \mathrm{nM}, 1 \mu \mathrm{M}$, and $2 \mu \mathrm{M}$ VIP were studied. We found that the VIP-mediated response was present at concentrations of $200 \mathrm{nM}(n=5)$ (Fig. 7A2) and was larger and probably maximal at $1 \mu \mathrm{M}$, because $2 \mu \mathrm{M}$ VIP induced no additional activation of $I_{\mathrm{H}}(n=6$; data not shown). These results suggest that the VIP response is not likely to be mediated by VPAC receptors, which have a high affinity for VIP (<10 nM) (cf. Vaudry, 2000). Consistent with this, the effects of VIP on $I_{\mathrm{H}}$ were not mimicked by the selective $\mathrm{VPAC}_{2}$ receptor agonist [Ala ${ }^{11,22,28}$ ] VIP (100 nM; $n=6 ; p>0.5$ vs controls) (Fig. 7C) but were reproduced by a low concentration of PACAP38, a broad spectrum agonist (10-100 nM) (Fig. $7 B 2$ vs $B 1, B 4, C)(p<0.05 ; n=6)$. The effects of PACAP38 on $I_{\mathrm{H}}$ current had a biophysical profile similar to that of VIP, including a right shift of half-activation potential $(6 \pm 1$ $\mathrm{mV} ; n=5$ ) and acceleration of activation time constant (Fig. $7 B 3)(n=6)$. In summary, these results suggest that $\mathrm{PAC}_{1}$ receptors mediated the effects of VIP on $I_{\mathrm{H}}$ in thalamocortical neurons.

Because the VIP and $\mathrm{PAC}_{1}$ receptors are known to induce elevation of intracellular cAMP via adenylyl cyclase, we subsequently tested whether exogenous application of membranepermeable cAMP analogs would reproduce and/or occlude VIP effects. Exogenously applied 8-cpt-cAMP alone mimicked the effects of PACAP38 and VIP on $I_{\mathrm{H}}$ in five of six neurons examined (Fig. $7 B 3$ vs $B 2, B 1, B 4, C$ ). Furthermore, the effects of 8 -cptcAMP on $I_{\mathrm{H}}$ were occluded by $1 \mu \mathrm{M}$ VIP (Fig. $\left.7 C\right)(n=6 ; p=1 \mathrm{vs}$ VIP alone in the same cells). These results suggest that VIP recep- 

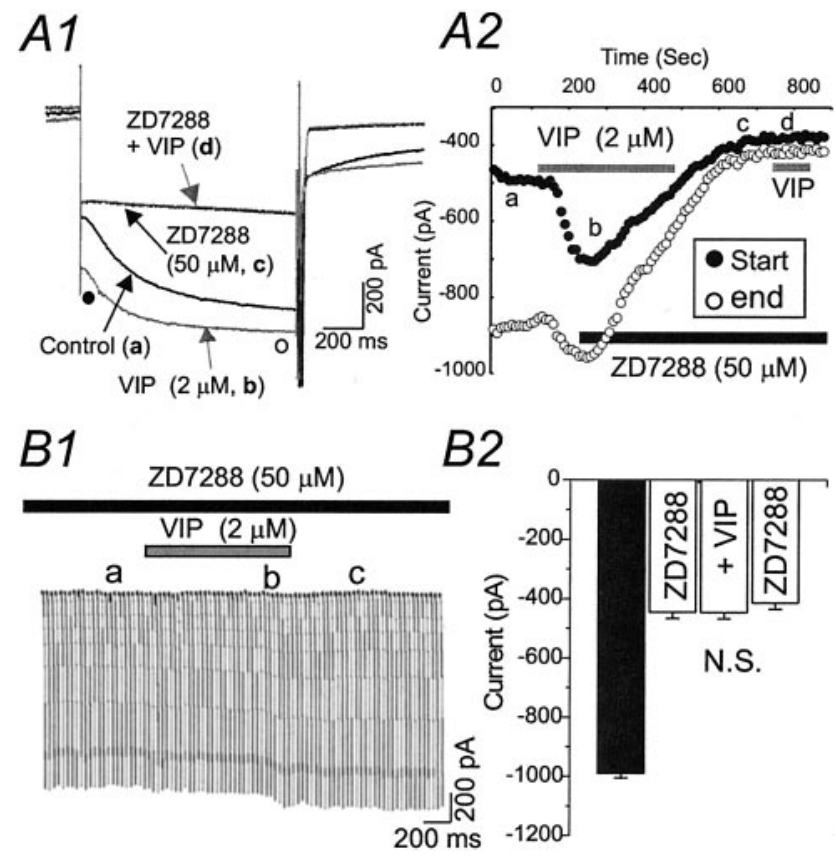

Figure 6. Effects of VIP on $I_{H}$ and membrane conductance are occluded by ZD7288. $A 1$, Currents elicited by hyperpolarizing steps to $-100 \mathrm{mV}$ from a holding potential of $-50 \mathrm{mV}$ under control conditions ( $a$, black trace), during the addition of $2 \mu \mathrm{MVIP}$ ( $b$, gray trace), during perfusion of $50 \mu \mathrm{m}$ ZD7288 (c, black trace), and during application of both ZD7288 and $2 \mu \mathrm{M}$ VIP ( $d$, gray trace). Traces in $A 1$ were obtained at points $a-d$ in A2. A2, Time series measurements in the cell of $A 1$, showing that activation of $I_{H}$ by VIP was blocked by ZD7288. ZD7288 perfusion eliminated VIP effects on both early (black circles, start) and late phases of $I_{H}$ (open circles, end). During ZD7288 perfusion, a second application of VIP (gray bar on the right below $d$ ) had no effect on $I_{H}$. Open and filled circles in $A 1$ and $A 2$ indicate the time of measurements. $B 1$, Current traces elicited by the voltage ramps $(-50$ to $-130 \mathrm{mV}$ over $2 \mathrm{sec}, 0.2 \mathrm{~Hz})$ shown in $B 2$ after a 10 min initial application of ZD7288 ( $a$ ), during the addition of $2 \mu \mathrm{MVIP}(b)$, and after VIP washout (c). B2, Graph of currents measured at $-100 \mathrm{mV}$ under control conditions (black bar), after perfusion of $\mathrm{ZD} 7288(50 \mu \mathrm{M})$, after perfusion of ZD7288 plus $2 \mu \mathrm{M} \mathrm{VIP}$, and ZD7288 alone after VIP washout ( $n=5$; NS vs ZD7288 alone).

tor activation, via elevation of intracellular cAMP levels, leads to activation of $I_{\mathrm{H}}$ channels in thalamocortical neurons.

\section{Discussion}

\section{Regulation of HCN channels by classical and} peptidergic neurotransmitters

$I_{\mathrm{H}}$ channels are encoded by a family of genes, including $H C N 1$, $\mathrm{HCN} 2, \mathrm{HCN} 3$, and HCN4. In rodent thalamic relay nuclei, abundant $\mathrm{HCN}_{2}$ and $\mathrm{HCN}_{4}$ mRNA were detected in mice (Moosmang et al., 1999; Santoro et al., 2000), but only $\mathrm{HCN}_{4}$ transcripts were found in rat relay nuclei (Monteggia et al., 2000). These HCN channels differ in their kinetics, steady-state voltage dependence, and the extent of modulation by cAMP (Wainger et al., 2001). For example, both $\mathrm{HCN}_{2}$ and $\mathrm{HCN}_{4}$ channels exhibit slow voltageand time-dependent activation kinetics compared with $\mathrm{HCN}_{1}$ channels. However, in expression systems, $\mathrm{HCN}_{4}$ channels showed slower activation than $\mathrm{HCN}_{2}$ channels, a less steep voltage dependence for activation, and less of a rightward shift of half-activation voltages by cAMP (Ludwig et al., 1999). In rat thalamocortical neurons, previous studies have characterized the properties of $I_{\mathrm{H}}$ and its modulation by neurotransmitter receptors (Pape and McCormick, 1989; McCormick and Pape, 1990a,b; for review, see Pape, 1996). The kinetics of $I_{\mathrm{H}}$ in our study is very similar to those described in these previous studies. For example, the half-activation membrane potential in our experiments was $-88.5 \pm 2.5 \mathrm{mV}$, similar to that reported previ- ously (Munsch and Pape, 1999). The time-dependent activation of $I_{\mathrm{H}}$ could be fitted with a single exponential equation with a mean time constant that varied from $100 \mathrm{msec}$ to $2 \mathrm{sec}$ (cf. McCormick and Pape, 1990a; Munsch and Pape, 1999). In mouse thalamocortical neurons, however, currents elicited by hyperpolarizing steps decay with a biphasic time course, rather than exhibiting a single exponential decay (Santoro et al., 2000). These discrepancies between $I_{\mathrm{H}}$ in mice versus rat relay neurons may be related to expression of different $\mathrm{HCN}$ genes $\left(\mathrm{HCN}_{2}\right.$ and $\mathrm{HCN}_{4}$ in mice vs more $\mathrm{HCN}_{4}$ in rats).

Our results show that PACAP38 peptide in nanomolar concentrations and VIP in micromolar concentrations produce robust activation of $I_{\mathrm{H}}$ in relay neurons. These peptides caused a shift of half-activation voltages $(+7 \mathrm{mV})$ toward more depolarized membrane potentials. These effects are quantitatively identical to the activation of $I_{\mathrm{H}}$ by $5-\mathrm{HT}$ and noradrenaline in thalamic neurons ( $+6 \mathrm{mV}$ shifts of $V_{1 / 2}$ ) (cf. McCormick and Pape, $1990 \mathrm{a}, \mathrm{b})$. Interestingly, in thalamocortical relay neurons, a variety of neurotransmitters (Pape and McCormick, 1989; McCormick and Pape, 1990a,b) and direct application of cAMP (Lüthi and McCormick, 1998, 1999) cause quantitatively very similar shifts of half-activation voltages (approximately $+7 \mathrm{mV}$ ) (for review, see Santoro and Tibbs, 1999). These data suggest that each of these neurotransmitters could elevate intracellular cAMP concentrations sufficiently to maximally shift $I_{\mathrm{H}}$ activation.

Our data also indicate that the rightward shift of voltagedependent activation by VIP had a strong effect on $I_{\mathrm{H}}$ and could elicit $60 \%$ increases in relative activation at physiologically relevant membrane potentials (between -70 and $-60 \mathrm{mV}$ ) (Figs. $4 B 1,5 B)$. Therefore, low concentrations of endogenous PACAP peptides could potentially alter thalamocortical neuron firing modes (Figs. 1C, 3A). Because peptidergic actions tend to be slower in onset and longer lasting compared with classical neurotransmitters (Jan and Jan, 1981), the regulation of $I_{\mathrm{H}}$ channels by PACAP suggests an additional and novel pathway through which thalamocortical activity may be regulated.

To our knowledge, other than the results presented here, there is very little evidence for upregulation of $I_{\mathrm{H}}$ by endogenous neuropeptides in the mammalian CNS. Results of several studies have shown the opposite effects of peptides, namely an inhibition of $I_{\mathrm{H}}$. For, example, opioids decrease $I_{\mathrm{H}}$ and a potassium current in hippocampal interneurons (Svoboda and Lupica, 1998), substance P inhibits $I_{\mathrm{H}}$ via neurokinin $\left(\mathrm{NK}_{1}\right)$ receptors in vagal sensory neurons (Jafri and Weinreich, 1998), and neurotensin inhibits $I_{\mathrm{H}}$ in the rat substantia nigra pars compacta (Cathala and Paupardin-Tritsch, 1997). The ability of neuropeptides to decrease $I_{\mathrm{H}}$ may be mediated by inhibition of adenylyl cyclase (Ingram and Williams, 1994) and activation of PKC pathways (cf. Cathala and Paupardin-Tritsch, 1997).

\section{VIP/PACAP $\mathrm{PAC}_{1}$ receptor-mediated actions in thalamus and} other parts of the brain

Despite the wide distribution of endogenous PACAP/VIP peptides in nerve terminals of the central and peripheral nervous systems, very little is known about the physiological roles of these peptides in the brain. Limited evidence suggests that these peptides can activate a range of G-protein-coupled receptors that then activate a number of downstream second messengers which, in turn, regulate neuronal excitability. For example, PACAP in nanomolar concentrations, via activation of $\mathrm{PAC}_{1}$ receptors, depolarizes rat sympathetic neurons by suppressing both potassium conductance and sodium influx. These effects are mediated by $\mathrm{G}_{\mathrm{q}}$ proteins and activation of phospholipase $\mathrm{C}$-dependent $\mathrm{IP}_{3}$ path- 

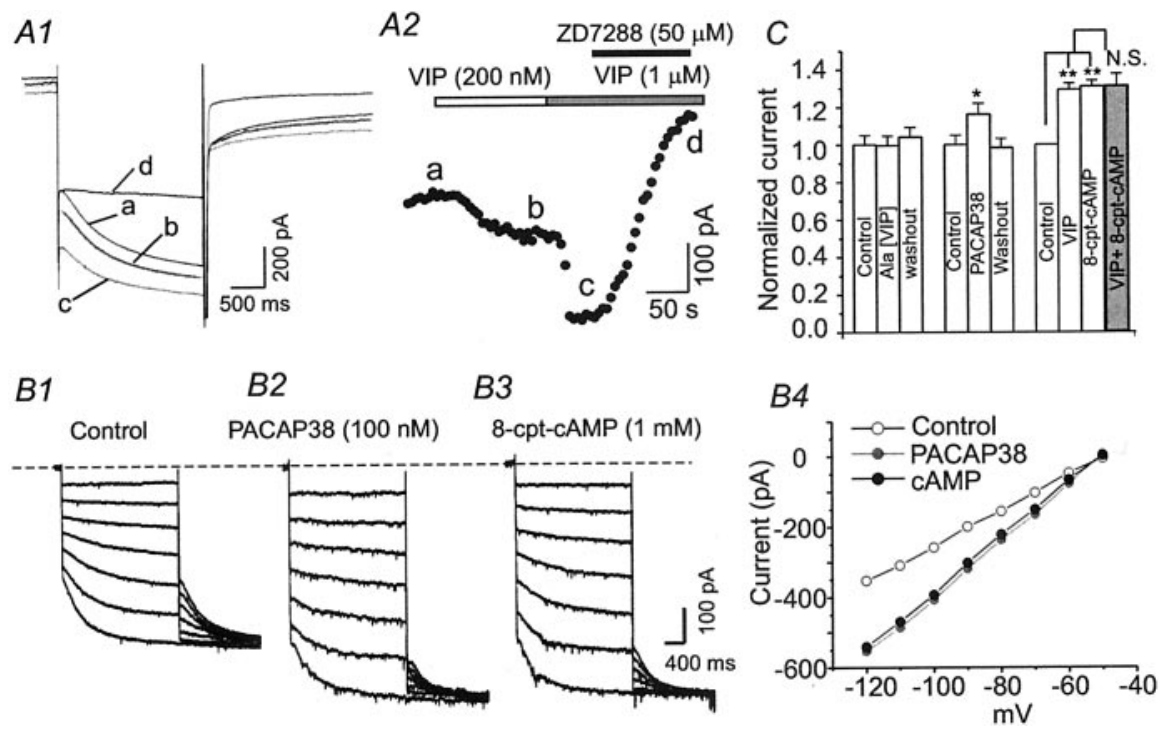

Figure 7. Pharmacological profile of VIP-mediated effects on $I_{H}$ and involvement of CAMP. $A 1$, Currents elicited by hyperpolarizing voltage steps to $-100 \mathrm{mV}$ from a holding potential of $-50 \mathrm{mV}$ under control conditions ( $a$ ), during the addition of $200 \mathrm{~nm}$ (b, gray trace) or $1 \mu \mathrm{M}$ (c) VIP, or during the addition of $1 \mu \mathrm{M}$ VIP with ZD7288 (d). Traces are obtained at points $a-d$ in A2. A2, Time series reflecting peak inward currents for the experiment in $A 1$. Bars indicate time of drug applications. $B, A$ family of current traces elicited by hyperpolarizing voltage steps ( $1 \mathrm{sec}$ ) from -60 to $-120 \mathrm{mV}$ in $10 \mathrm{mV}$ increments from a different neuron under control conditions (B1), during perfusion of $100 \mathrm{~nm}$ PACAP38 (B2), and 20 min after PACAP38 washout during perfusion of 8-cpt-CAMP (1 $\mathrm{mm} ; B 3) . B 4, I-V$ plots of peak inward currents obtained from the neuron in $B 1-B 3$. C, Summary graph of normalized currents elicited by hyperpolarizing steps to $-100 \mathrm{mV}$ in different experimental conditions $\left(n=6\right.$ for each condition; ${ }^{*} p<0.05$ and ${ }^{* *} p<0.01$ vs controls).

ways (Beaudet et al., 2000). Interestingly, also in rat sympathetic neurons, a high concentration of VIP $(10 \mu \mathrm{M})$ produced choleratoxin-sensitive voltage-dependent inhibition of N-type calcium channels (Zhu and Yakel, 1997). However, it is not known which receptors mediate this response. These two studies suggest that multiple neuropeptidergic receptors can coexist within a neuron and exert different physiological functions. In another very relevant study, VIP was shown to evoke excitatory actions in medial pontine reticular formation neurons that are implicated in the control of the sleep-wakefulness cycle. The effects of VIP on these neurons occurred at a low concentration $(<100 \mathrm{nM})$ and were mediated by cAMP, protein kinase A, and sodium-dependent conductance (Kohlmeier and Reiner, 1999). In hippocampal pyramidal neurons, VIP modulates slow AHP currents (SK currents) by activation of adenylyl cyclase and cAMP (Haug and Storm, 2000).

Three PACAP family peptide receptors, belonging to the seven transmembrane receptor G-protein-coupled receptor superfamily, have been cloned to date. On the basis of pharmacological profiles, these receptors can be subgrouped into two classes: type I receptors, which include $\mathrm{PAC}_{1}$ receptors, and type II receptors, which include $\mathrm{VPAC}_{1}$ and $\mathrm{VPAC}_{2}$ receptors. Type I receptors show different binding affinities for VIP (>500 nM) and PACAP38 (0.5 nM), whereas type II receptors $\left(\mathrm{VPAC}_{1}\right.$ and $\left.\mathrm{VPAC}_{2}\right)$ show similar binding affinities for VIP $(1 \mathrm{nM})$ and PACAP (1 nM). In virtually all thalamic nuclei, $\mathrm{PAC}_{1}$ receptors are highly expressed, whereas $\mathrm{VPAC}_{1}$ receptors are not expressed in the thalamus. Moderate levels of $\mathrm{VPAC}_{2}$ receptors have been detected in the thalamus, but their distribution is unclear (for review, see Vaudry et al., 2000). We found that the modulation of $I_{\mathrm{H}}$ by VIP was not maximal at concentrations of $200 \mathrm{~nm}$. The selective $\mathrm{VPAC}_{2}$ receptor agonist [Ala ${ }^{11,22,28}$ ] VIP (100 nM) overall had no significant effects on $I_{\mathrm{H}}$ modulation. Therefore, we conclude that the effects of VIP and PACAP38 on $I_{\mathrm{H}}$ in thalamocortical neurons are predominantly mediated by $\mathrm{PAC}_{1}$ receptors. Our results provide the first example of activation of $I_{\mathrm{H}}$ channels by an endogenous neuropeptide in the thalamus, an action that may influence both normal and pathophysiological thalamocorticalrhythm generation and may have important resultant behavioral effects on the regulation of sensory processing and modulation of sleep-wake cycles.

Behavioral studies have shown that intracerebral injection of PACAP (Fang et al., 1995) or VIP (Bourgin et al., 1997) enhances REM sleep in several species, including rats. In humans, intravenous administration of VIP caused an increased duration of REM periods and an increase in the REM-to-non-REM ratio (Murck et al., 1996). However, the mechanisms underlying the PACAP/VIP-mediated behavioral effects are not entirely clear. Direct microinjection of PACAP or VIP into several brainstem regions, including the oral pontine reticular nucleus, results in long-term enhancement of REM sleep (Bourgin et al., 1997; Ahnaou et al., 2000).

This is likely mediated in pontine reticular formation neurons in part by VIP receptors, cAMP, and a sodium conductance (Kohlmeiet and Reiner, 1999). Here, we show that in the thalamus, PACAP and VIP caused a robust depolarization of thalamocortical neurons that could result in transformation of firing mode from burst to tonic. The transition from sleep (nonREM) to waking or REM sleep is known to be associated with steady depolarization of thalamocortical neurons and thalamic reticular neurons (Hirsch et al., 1983; for review, see Steriade and McCarley, 1990; McCormick and Bal, 1997). Therefore, we speculate that PACAP/VIP receptor activation in the thalamus may play a supportive role in the regulation of REM sleep.

\section{References}

Ahnaou A, Laporte AM, Ballet S, Escourrou P, Hamon M, Adrien J, Bourgin $\mathrm{P}$ (2000) Muscarinic and PACAP receptor interactions at pontine level in the rat: significance for REM sleep regulation. Eur J Neurosci 12:4496-4504.

Bayer L, Eggermann E, Saint-Mleux B, Machard D, Jones BE, Muhlethaler M, Serafin M (2002) Selective action of orexin (hypocretin) on nonspecific thalamocortical projection neurons. J Neurosci 22:7835-7839.

Beaudet MM, Parsons RL, Braas KM, May V (2000) Mechanisms mediating pituitary adenylate cyclase-activating polypeptide depolarization of rat sympathetic neurons. J Neurosci 20:7353-7361.

BoSmith RE, Briggs I, Sturgess NC (1993) Inhibitory actions of ZENECA ZD7288 on whole-cell hyperpolarization activated inward current (If) in guinea-pig dissociated sinoatrial node cells. Br J Pharmacol 110:343-349.

Bourgin P, Lebrand C, Escourrou P, Gaultier C, Franc B, Hamon M, Adrien J (1997) Vasoactive intestinal polypeptide microinjections into the oral pontine tegmentum enhance rapid eye movement sleep in the rat. Neuroscience 77:351-360.

Burgunder JM, Heyberger B, Lauterburg T (1999) Thalamic reticular nucleus parcellation delineated by VIP and TRH gene expression in the rat. J Chem Neuroanat 17:147-152.

Cathala L, Paupardin-Tritsch D (1997) Neurotensin inhibition of the hyperpolarization-activated cation current $\left(\mathrm{I}_{\mathrm{H}}\right)$ in the rat substantia nigra 
pars compacta implicates the protein kinase C pathway. J Physiol (Lond) 503:87-97.

Cox CL, Huguenard JR, Prince DA (1995) Cholecystokinin depolarizes rat thalamic reticular neurons by suppressing a $\mathrm{K}^{+}$conductance. J Neurophysiol 74:990-1000.

Edwards FA, Konnerth A, Sakmann B, Takahashi T (1989) A thin slice preparation for patch clamp recordings from neurones of the mammalian central nervous system. Pflügers Arch 14:600-612.

Fang J, Payne L, Krueger JM (1995) Pituitary adenylate cyclase activating polypeptide enhances rapid eye movement sleep in rats. Brain Res 686:23-28.

Haug T, Storm JF (2000) Protein kinase A mediates the modulation of the slow $\mathrm{Ca}(2+)$-dependent $\mathrm{K}(+)$ current, $\mathrm{I}(\mathrm{sAHP})$, by the neuropeptides CRF, VIP, and CGRP in hippocampal pyramidal neurons. J Neurophysiol 83:2071-2079.

Hirsch JC, Fourment A, Marc ME (1983) Sleep-related variations of membrane potential in the lateral geniculate body relay neurons of the cat. Brain Res 259:308-312.

Ingram SL, Williams JT (1994) Opioid inhibition of $\left(\mathrm{I}_{\mathrm{H}}\right)$ via adenylyl cyclase. Neuron 13:179-186.

Jafri MS, Weinreich D (1998) Substance P regulates $\left(\mathrm{I}_{\mathrm{H}}\right)$ via a NK-1 receptor in vagal sensory neurons of the ferret. J Neurophysiol 79:769-777.

Jahnsen H, Llinas R (1984a) Electrophysiological properties of guinea-pig thalamic neurones: an in vitro study. J Physiol (Lond) 349:205-226.

Jahnsen H, Llinas R (1984b) Ionic basis for the electro-responsiveness and oscillatory properties of guinea-pig thalamic neurones in vitro. J Physiol (Lond) 349:227-247.

Jan LY, Jan YN (1981) Role of an LHRH-like peptide as a neurotransmitter in sympathetic ganglia of the frog. Fed Proc 40:2560-2564.

Kohlmeier KA, Reiner PB (1999) Noradrenaline excites non-cholinergic laterodorsal tegmental neurons via two distinct mechanisms. Neuroscience 93:619-630.

Köves K, Arimura A, Gorcs TG, Somogyvari-Vigh A (1991) Comparative distribution of immunoreactive pituitary adenylate cyclase activating polypeptide and vasoactive intestinal polypeptide in rat forebrain. Neuroendocrinology 54:159-169.

Ludwig A, Zong X, Jeglitsch M, Hofmann F, Biel M (1998) A family of hyperpolarization-activated mammalian cation channels. Nature 393:587-591.

Ludwig A, Zong X, Stieber J, Hullin R, Hofmann F, Biel M (1999) Two pacemaker channels from human heart with profoundly different activation kinetics. EMBO J 18:2323-2329.

Lüthi A, McCormick DA (1998) Periodicity of thalamic synchronized oscillations: the role of $\mathrm{Ca}^{2+}$-mediated upregulation of $\left(\mathrm{I}_{\mathrm{H}}\right)$. Neuron 20:553-563.

Lüthi A, McCormick DA (1999) Modulation of a pacemaker current through $\mathrm{Ca}(2+)$-induced stimulation of cAMP production. Nat Neurosci 2:634-641.

McCormick DA (1992a) Cellular mechanisms underlying cholinergic and noradrenergic modulation of neuronal firing mode in the cat and guinea pig dorsal lateral geniculate nucleus. J Neurosci 12:278-289.

McCormick DA (1992b) Neurotransmitter actions in the thalamus and cerebral cortex and their role in neuromodulation of thalamocortical activity. Prog Neurobiol 39:337-388.

McCormick DA, Bal T (1997) Sleep and arousal: thalamocortical mechanisms. Annu Rev Neurosci 20:185-215.

McCormick DA, Pape HC (1990a) Properties of a hyperpolarizationactivated cation current and its role in rhythmic oscillation in thalamic relay neurones. J Physiol (Lond) 431:291-318.

McCormick DA, Pape HC (1990b) Noradrenergic and serotonergic modu- lation of a hyperpolarization-activated cation current in thalamic relay neurones. J Physiol (Lond) 431:319-342.

McCormick DA, Prince DA (1987) Neurotransmitter modulation of thalamic neuronal firing pattern. J Mind Behav [Suppl] 8:573-590.

McCormick DA, Prince DA (1988) Noradrenergic modulation of firing pattern in guinea pig and cat thalamic neurons in vitro. J Neurophysiol 59:978-996.

McCormick DA, Williamson A (1991) Modulation of neuronal firing mode in cat and guinea pig LGNd by histamine: possible cellular mechanisms of histaminergic control of arousal. J Neurosci 11:3188-3199.

Meis S, Munsch T, Pape HC (2002) Antioscillatory effects of nociceptin/ orphanin FQ in synaptic networks of the rat thalamus. J Neurosci 22:718-727.

Monteggia LM, Eisch AJ, Tang MD, Kaczmarek LK, Nestler EJ (2000) Cloning and localization of the hyperpolarization-activated cyclic nucleotidegated channel family in rat brain. Brain Res Mol Brain Res 81:129-139.

Moosmang S, Biel M, Hofmann F, Ludwig A (1999) Differential distribution of four hyperpolarization-activated cation channels in mouse brain. Biol Chem 380:975-980.

Munsch T, Pape HC (1999) Modulation of the hyperpolarization-activated cation current of rat thalamic relay neurones by intracellular $\mathrm{pH}$. J Physiol (Lond) 519:493-504.

Murck H, Guldner J, Colla-Muller M, Frieboes RM, Schier T, Wiedemann K, Holsboer F, Steiger A (1996) VIP decelerates non-REM-REM cycles and modulates hormone secretion during sleep in men. Am J Physiol 271:R905-R911.

Pape HC (1996) Queer current and pacemaker: the hyperpolarizationactivated cation current in neurons. Annu Rev Physiol 58:299-327.

Pape HC, McCormick DA (1989) Noradrenaline and serotonin selectively modulate thalamic burst firing by enhancing a hyperpolarizationactivated cation current. Nature 340:715-718.

Santoro B, Tibbs GR (1999) The HCN gene family: molecular basis of the hyperpolarization-activated pacemaker channels. Ann NY Acad Sci 868:741-764.

Santoro B, Chen S, Luthi A, Pavlidis P, Shumyatsky GP, Tibbs GR, Siegelbaum SA (2000) Molecular and functional heterogeneity of hyperpolarization-activated pacemaker channels in the mouse CNS. J Neurosci 20:5264-5275.

Steriade M, McCarley RW (1990) Brainstem control of wakefulness and sleep. New York: Plenum.

Sun QQ, Huguenard JR, Prince DA (2001) Neuropeptide Y receptors differentially modulate $\mathrm{G}$-protein-activated inwardly rectifying $\mathrm{K}^{+}$channels and high-voltage-activated $\mathrm{Ca}^{2+}$ channels in rat thalamic neurons. J Physiol (Lond) 531:67-79.

Sun QQ, Huguenard JR, Prince DA (2002) Somatostatin inhibits thalamic network oscillations in vitro: actions on the GABAergic neurons of the reticular nucleus. J Neurosci 22:5374-5386.

Svoboda KR, Lupica CR (1998) Opioid inhibition of hippocampal interneurons via modulation of potassium and hyperpolarization-activated cation $\left(I_{\mathrm{H}}\right)$ currents. J Neurosci 18:7084-7098.

Vaudry D, Gonzalez BJ, Basille M, Yon L, Fournier A, Vaudry H (2000) Pituitary adenylate cyclase-activating polypeptide and its receptors: from structure to functions. Pharmacol Rev 52:269-324.

Wainger BJ, DeGennaro M, Santoro B, Siegelbaum SA, Tibbs GR (2001) Molecular mechanism of cAMP modulation of $\mathrm{HCN}$ pacemaker channels. Nature 41:805-810.

Zhu Y, Yakel JL (1997) Modulation of $\mathrm{Ca}^{2+}$ currents by various $\mathrm{G}$ proteincoupled receptors in sympathetic neurons of male rat pelvic ganglia. J Neurophysiol 78:780-789. 